\title{
A disseminação do uso das novas tecnologias da informação e comunicação: efeitos na sociedade
}

New information and communication technologies (ICTs) dissemination: social effects

\author{
Aleixina Maria Lopes Andalécio \\ Mestre em Ciência da Informação (UFMG) e Analista de Sistemas do Centro de Computação da UFMG \\ E-mail:xina@cecom.ufmg.br
}

Resumo

Tecnologias, apesar de serem sempre produto da sociedade, também contribuem para sua conformação e transformação. Este artigo levanta alguns dos efeitos que a disseminação do uso das novas tecnologias de informação e comunicação provocam hoje na vida pessoal, profissional e social das pessoas, ou seja, na nossa sociedade. 0 que fica claro é que tais efeitos precisam ainda ser mais bem estudados, pois essas tecnologias ainda são um fenômeno muito recente na história do homem.

Palavras-chave: tecnologias de informação e comunicação, efeitos, sociedade.

Ao longo dos milhares de anos de sua história na Terra, o homem aprendeu a desenvolver instrumentos e ferramentas que o ajudassem a superar as dificuldades encontradas ao lidar com o mundo e lhe permitissem aumentar sua capacidade de intervir nesse mundo. Essa também é a origem das tecnologias de informação e comunicação, que surgiram em função da necessidade humana de lidar com o crescimento desenfreado da produção de informação no mundo contemporâneo (MARQUES NETO, 2002).

O computador náo é único representante das tecnologias de informação e comunicação, entre as quais também encontramos o papel, arquivos, fichários, fax, telefone, livro, jornal, correio, televisão, telex, copiadoras, projetores (de slides, de transparências, de filmes e multimídia), mas pode ser considerado, hoje, o principal deles. Isso talvez se deva à sua possibilidade de utilização na solução de diversos tipos de problemas relacionados à informação e de expandir a capacidade humana de armazenar dados (MARQUES NETO, 2002).

A Internet, a rede de computadores capazes de se comunicar uns com os outros, apesar de ser um fenômeno recente na história da humanidade, tendo surgido a partir de 1969 , tornouse um meio para todas as formas de comunicação, de interação e de organização social (CASTELLS, 2003). Ela é, hoje, o mais conhecido representante das novas tecnologias de informaçáo e comunicaçáo e, segundo Castells, "não precisa de explicação, pois já sabemos o que é Internet" (CASTELLS, 2003, p. 255).

Não há como ignorar a participaçáo das tecnologias de informação e comunicaçáo na sociedade atual, o que traz, é claro, efeitos para essa sociedade, efeitos estes que têm sido alvo de vários estudos. Palmquist (1992) relacionou trabalhos que enfocam como as tecnologias baseadas em computadores afetam a vida dos indivíduos, os quais se detêm sobre as transformaçóes que elas trouxeram para a cultura, a vida doméstica, a vida comunitária, o exercício profissional, as interaçóes sociais, a qualidade de vida e satisfaçáo no trabalho, e o exercício da cidadania. É esse tipo de efeito que se pretende discutir aqui.

Um breve histórico

As chamadas tecnologias da informação, também agregadas sob o nome de informática, se inseriram na vida das pessoas com uma velocidade muito grande. Os primeiros computadores surgiram em 1945 , sendo que o primeiro computador de uso geral, o ENIAC, foi apresentado ao público em 1946 (LÉVY, 1999). 
Durante muito tempo, computadores foram equipamentos enormes e caros, aos quais apenas um grupo restrito de profissionais tinha acesso, cenário que mudou completamente a partir da década de 1970. Conforme nos apresentam Lévy (1999) e Castells (1999), o surgimento do microprocessador, em 1971, provocou uma verdadeira revolução no campo profissional, social e pessoal. Hoje, o computador está nas casas das pessoas, e um modelo que cabe na palma da mão tem mais capacidade de processar e armazenar informaçóes que qualquer computador de grande porte (mainframe) existente à época do surgimento do microprocessador. A utilização dos computadores também foi simplificada com o desenvolvimento de programas (software), de controle (sistemas operacionais, como o Windows), de aplicação (editores de texto, planilhas eletrônicas etc.), além de novas interfaces com o usuário, como monitores, teclados, impressoras etc., e o uso de ícones, em vez de comandos complicados, permitindo seu uso por qualquer pessoa, sem a necessidade de ser um profissional especializado na área de informática (LÉVY, 1993).

Nos anos 1980, a informática começou a fundir-se com as telecomunicações, a editoração, o cinema e a televisão (LÉVY, 1999), tornando-se presente em atividades cotidianas das pessoas, tanto na vida profissional quanto na vida privada. A esses avanços somou-se a possibilidade de interligar os computadores em rede, que multiplica, mediante o compartilhamento, a capacidade de processamento e armazenamento de informaçōes. A Internet, rede inicialmente desenvolvida com objetivos militares, mas que logo foi adotada pela comunidade em geral, é o exemplo mais conhecido desse tipo de conexẫo, e teve seu uso disseminado mais rapidamente que qualquer outra tecnologia de comunicação até então criada pelo homem. Em 1995, uma pesquisa dava conta da existência de cerca de 350 milhôes de usuários da Internet, enquanto previsōes conservadoras para o período 2005-2007 indicam um número de 2 bilhóes de usuários, ou seja, a terça parte da população do planeta, sendo que nas naçôes mais desenvolvidas a taxa de penetração estará entre $75 \%$ e $80 \%$ da população (CASTELLS, 2003).

\section{Efeitos na sociabilidade}

As novas formas de sociabilidade possibilitadas pelo desenvolvimento das tecnologias de informação e comunicação estão sendo estudadas por pesquisadores de várias áreas. Conforme apresentado por Lévy (1999), esse desenvolvimento propiciou o surgimento do ciberespaço, "novo espaço de comunicação, de sociabilidade, de organização e de transação, mas também novo mercado da informaçäo e do conhecimento" (p.32). O intercâmbio entre indivíduos passou a prescindir do compartilhamento de um mesmo espaço. Câmeras de vídeo e outros dispositivos multimídia conectados à Internet permitem a transmissão instantânea de imagens e sons entre pontos distantes entre si, possibilitando a realização de contatos pessoais mesmo que os indivíduos envolvidos na interação estejam fisicamente distantes. Um exemplo disso é a realização de teleconferências, cuja utilização começa a se estender também às interaçōes pessoais. Isso pode tornar necessário, inclusive, rever o conceito de interaçáo face a face utilizado por Berger e Luckmann (2002), para os quais a realidade da vida cotidiana é partilhada e a forma mais importante de fazê-lo é a interação face a face, aquela na qual colidem o aqui e agora de indivíduos diferentes. Para esses autores, apenas na situação face a face o outro é plenamente real. A necessidade de revisáo se apresenta em função do desencaixe propiciado pelas novas tecnologias da informação e da comunicaçăo, pois o intercâmbio entre as expressividades de indivíduos diferentes passou a prescindir do compartilhamento de um mesmo espaço, o aqui propugnado por Berger e Luckmann (2002).

Para Martín-Barbero (2003), as redes eletrônicas são o espaço no qual circulam o capital, as finanças, e também um lugar de encontro "de minorias e comunidades 
marginalizadas ou de coletividades de pesquisa e trabalho educativo ou artístico" (MARTÍN-BARBERO, 2003, p.59). Grupos virtuais criados nas redes eletrônicas podem dar origem, principalmente nas grandes cidades, a encontros e ações, tornando-se grupos territorializados. Para ele, a comunicação midiática aparece "como parte das desterritorializaçōes e relocalizaçôes que acarretam as migraçōes sociais $e$ as fragmentaçôes culturais da vida urbana; do campo de tensōes entre tradição e inovação, entre a grande arte e as culturas do povo; do espaço em que se redefine o alcance do público e o sentido da democracia" (MARTÍNBARBERO, 2003, p.64).

Martín-Barbero (2003) acrescenta que é necessário buscar investigar e compreender os novos modos de se estar junto, principalmente entre as geraçôes mais novas, que se conformam em grupalidades mestiças nos modos de falar e vestir e na música que fazem e ouvem; e as relaçōes entre o sistema educativo e o ambiente educativo difuso $e$ descentralizado constituído pelos meios de comunicação. As grupalidades dos jovens podem ser, inclusive, virtuais, pois eles "vivem hoje a emergência das novas sensibilidades, dotadas de uma especial empatia com a cultura tecnológica, que vai da informaçâo absorvida pelo adolescente em sua relação com a televisão à facilidade para mover-se na complexidade das redes informáticas" (MARTÍN-BARBERO, 2003, p.66). Os jovens apresentam, segundo o autor, uma empatia cognitiva e uma cumplicidade expressiva na relação com as tecnologias audiovisuais e informáticas, que usam com facilidade e nas quais encontram seu idioma e seu ritmo, levando à produção de novas comunidades, que correspondem a novos modos de perceber e de narrar a identidade.

As tecnologias de informação $\mathrm{e}$ comunicação abriram novas possibilidades de sociabilidade, o que foi comprovado por Bretas (2000), em estudo sobre interações telemáticas, realizado com adolescentes de três escolas de Belo Horizonte. Para essa autora, a Internet, além de ser o principal vetor da globalização, com grande reflexo na economia, é também "um novo espaço de socialização do conhecimento e de novas configuraçôes para o convivio social" (BRETAS, 2000, p.202), "envolvendo pessoas em relacionamentos até então não concebidos" (BRETAS, 2000, p.39). As regras da interação nessa instância diferem daquelas das relaçóes presenciais, pois abre-se, inclusive, a possibilidade de simulaçóes de relacionamentos.

Em 1996, Palacios chamou a atenção para a necessidade de se estudar as formas de sociabilidade surgidas em decorrência da "incorporą̧āo de crescentes parcelas da população, em todo mundo, a esta nova forma de comunicar e vivenciar a realidade que säo as redes telemáticas, com todos os seus efeitos sobre o cotidiano das pessoas" (PALACIOS, 1996, p.91). Esse autor levantou alguns pontos que considera merecedores de discussão: a junção entre comunicação massiva e interatividade promovida pela explosão telemática; a apropriaçáo cotidiana da técnica pelas comunidades virtuais, eliminando a clivagem entre cultura e técnica; a inversão do processo de formação de laços nas comunidades virtuais, nas quais as pessoas se conhecem primeiro e só depois se encontram fisicamente, o que pode nem acontecer; e a interação entre imagens projetadas, "desencarnadas", independentes de um corpo físico (PALACIOS, 1996).

Para Ribeiro (2001), as práticas sociais no mundo virtual ainda são incipientes e suas características estão em processo de definição, o mesmo acontecendo com a avaliação de seus efeitos sobre a vida cotidiana dos participantes dessas novas formas de relacionamento. Para esse autor, o ciberespaço pode ser visto como um "não-lugar", um espaço de comunicaçáo pura, nas qual as relaçóes são vivenciadas mediante construçóes imaginárias, mediadas pelo computador. Não há papéis pré-estabelecidos a seguir, o próprio cibernauta (aquele que navega nos mares cibernéticos) é quem determina e formata os papéis que exercerá e onde eles serăo inseridos. Também é esse usuário do ciberespaço que escolhe com quem e quando quer se relacionar, o que é muito mais difícil nas relaçôes face a face.

Lemos (2002) é outro pesquisador 
que tem se debruçado sobre aspectos da vida social nas redes telemáticas, a chamada ciber-socialidade. Esse autor considera a cibercultura como produto social e cultural da sinergia entre a sociabilidade estética contemporânea (definida por ligaçōes orgânicas, efêmeras e simbólicas) e as tecnologias microeletrônicas. Como as formas de uma determinada sociedade se cristalizam em objetos técnicos, instituiçōes e imaginário, a cibercultura seria a expressão cotidiana da rebeldia contra as formas instituídas e cristalizadas da vida social que se impõe numa forma técnica, em um mundo saturado de objetos técnicos. Então, a tecnologia moderna, associada à racionalidade e à objetividade, passa a ser utilizada como instrumento para compartilhamento de emoçôes, convivência e formação comunitária. $\mathrm{O}$ que vemos são equipamentos criados para funcionarem como máquinas de calcular passarem a potencializar "o lúdico, a efervescência comunitária e a apropriação artística" (LEMOS, 2002, p.112).

\section{Efeitos cognitivos e comportamentais}

Muitos autores têm se interessado pelos efeitos cognitivos e comportamentais associados à disseminação do uso das novas tecnologias da informação e da comunicação. Martín-Barbero (2003) defende que hoje é necessária uma mudança nas categorias com as quais pensamos o espaço, já que as novas tecnologias (satélites, informática, televisão e outras) estão transformando o sentido do lugar no mundo, criando um mundo intercomunicado.

Para Lévy (1993), o mundo das telecomunicações e da informática leva a novas maneiras de pensar e de conviver, nas quais "escrita, leitura, visão, audição, criação, aprendizagem são capturados por uma informática cada vez mais avançada" (LÉVY, 1993, p.7). Para ele, a velocidade de mudança das bases do funcionamento social e das atividades cognitivas não passa despercebida, forçando uma revisão da filosofia do conhecimento e uma análise da articulação entre gêneros de conhecimento e tecnologias intelectuais, uma vez que "certas técnicas de armazenamento e de processamento das representaçōes tornam possiveis ou condicionam certas evoluçōes culturais" (LÉVY, 1993, p.10). Para Lévy (1993), as conseqüências do sucesso dos instrumentos de comunicação e dos computadores ainda não foram analisadas de forma suficiente, mas já está claro que esta época é um dos momentos em que uma nova configuração técnica leva a um novo estilo de humanidade. Também Castells (2003) apresenta a Internet como um "meio de comunicação que constitui a forma organizativa de nossas sociedades" (CASTELLS, 2003, p.287), pois estas seriam construídas em torno de redes de informação que utilizam a tecnologia microeletrônica que a Internet disponibiliza.

Oliveira (2003) considera que os sistemas de informaçáo disponibilizados na Internet passaram a fazer parte da vida e do trabalho das pessoas, mas que a incorporação das novas tecnologias aos hábitos envolve mudanças de comportamento que requerem um lento amadurecimento. Entretanto, esse novo ambiente altera a inserção social das pessoas, por possibilitar uma maior independência dos indivíduos em relação ao trabalho em locais fixos e em grandes grupos, dando lugar ao trabalho em pequenos escritórios ou em casa. E alguns outros problemas podem advir disso: tendência ao isolamento, falta do aprendizado social por convivência e perda de tempo com a leitura de grande carga de mensagens eletrônicas e outras atividades acessórias.

É necessário lembrar que, como muitos outros instrumentos desenvolvidos pelo homem, as tecnologias de informaçáo e comunicação contribuem para a superação de dificuldades encontradas ao lidar com o mundo, no caso, com o crescimento desenfreado da produção de informação (MARQUES NETO, 2002), mas podem gerar outras. Menou (1999) chama a atenção para dificuldades encontradas ao se realizar estudos sobre o impacto da Internet, os quais, apesar disso, estão proliferando em ritmo só 
comparável ao crescimento da própria Internet: a noção de impacto, em si; a fascinação pela tecnologia; a impossibilidade de separar a Internet de outras tecnologias da informação e da comunicação, bem como de fatores ambientais; identificação e rastreamento de usuários; falta de esquemas e modelos conceituais estabelecidos; fragilidade das definiçōes; variedade de métodos e abordagens; singularidade dos estudos; e a escassez de estudos longitudinais, devida ao fato de a Internet ser ainda uma experiência recente. Esse autor defende que as mudanças produzidas pela Internet na vida das pessoas só poderão ser mais bem compreendidas pela acumulação de evidências parciais e sugere algumas iniciativas para se chegar a isso: inventariar os grupos de pesquisa relacionados e facilitar sua conexão em rede; construir e manter portal para facilitar o acesso à literatura, à biblioteca digital e ao banco de dados sobre o tema; promover esforço cooperativo para coligir, clarificar e reconciliar os vários modelos e esquemas; inventariar, rever e indicar métodos adequados; construir agenda de pesquisa e facilitar a interação entre grupos de pesquisa, indústrias $\mathrm{e}$ usuários, visando o desenvolvimento de estudos combinados ou comparativos.

\section{Efeitos físicos e mentais}

No que diz respeito às mudanças físicas provocadas pelo uso de computadores e da Internet, Menou (1999) acentua ainda que elas precisam ser mais bem estudadas, já que são priorizados estudos sobre mudanças comportamentais. Um exemplo desse efeito é a possibilidade de que a geração que está crescendo no ambiente informatizado venha a apresentar deficiências psicomotoras. Weil (2000) também apresenta vários aspectos patogênicos relacionados com o uso

${ }^{1}$ http://www1.folha.uol.com. br/folha/informatica/ ult124u12165.shtml

${ }^{2}$ http://veja.abril.com.br/030304/ P_085.html sutil entre o computador e o ser humano (denominada simbiose neuroci-bernética); neurose do virtual, com dificuldades em lidar com a realidade do cotidiano; divulgação da mentalidade violenta; desequilíbrio dos hemisférios cerebrais; possibilidade de atrofia da função numérica da mente humana; e frustraçōes nas comunicações e relações humanas. Bawa (1997) buscou identificar e discutir problemas de saúde que podem estar relacionados com o uso do computador, tais como o estresse provocado pela interação com o computador, lesōes por esforços repetitivos, efeitos da radiação emitida pelo monitor e fadiga visual provocada pela leitura na tela. Essa autora apresenta também medidas para prevenir e tratar os problemas de saúde relacionados com o computador.

$\mathrm{O}$ uso sem controle de tecnologias de informação e comunicação pode acarretar problemas de saúde, já tendo até sido veiculadas na mídia notícias de mortes de usuários de computador e Internet provocadas por trombose venosa aguda devida à permanência por muitas horas seguidas sentados diante da tela ${ }^{1}$. Entretanto, algumas das preocupaçōes manifestadas quando começou a disseminação dessas ferramentas, como as de que as pessoas deixariam de relacionar-se, que se tornariam ainda mais sedentárias e que poderiam perder o contato com a realidade, parecem ter sido exageradas. Conforme matéria publicada na edição 1843 da revista Veja, de 3 de março de 2004, uma pesquisa feita nos Estados Unidos mostrou que os internautas praticam mais exercícios físicos, lêem mais livros e têm vida social mais agitada do que aqueles, de mesmo nível socioeconômico, que não utilizam a rede, o que parece estar relacionado com a economia de tempo propiciada pelo uso das tenologias e a facilidade de acesso a informaçōes sobre saúde e cultura ${ }^{2}$. Talvez esses resultados possam servir como argumento para contestar a posição de Lucien Sfez (1996), para quem a sedução pelas tecnologias da comunicação poderia propiciar o aparecimento do que ele chamou de 
tautismo, neologismo formado pela contração de tautologia (proposição que tem por sujeito e predicado um mesmo conceito $^{3}$ ) e autismo (o isolamento esquizofrênico, a não-comunicaçăo), criado para designar a confusão entre representação e expressão. No contexto do uso das tecnologias de informaçăo e comunicaçăo, principalmente o computador e a Internet, o resultado seria o isolamento social, o aprisionamento em um mundo virtual, o desligamento do mundo real, o que não parece estar acontecendo.

\section{Efeitos encontrados em uma pesquisa de campo}

O trabalho de campo de minha pesquisa no mestrado incluiu entrevistas com doutorandos e recém-doutores do curso de doutorado em Ciências Humanas: Sociologia e Política, da Faculdade de Filosofia e Ciências Humanas da UFMG (FAFICH/ UFMG), com o objetivo de verificar como as ferramentas de tecnologia de informaçăo e comunicação estão sendo utilizadas como instrumentos auxiliares no trabalho de pesquisa nas Ciências Sociais. Foram entrevistados dez participantes do programa, sendo que três já haviam concluído seu doutorado e três eram professores do curso. Foi também incluído na amostra um aluno do mestrado, apontado por participantes do doutorado como alguém que fazia uso intensivo das ferramentas de técnologia de informação e comunicação. Assim, no total, foram entrevistados catorze sujeitos, dos quais cinco $(35,7 \%)$ são do sexo feminino; oito $(57,1 \%)$ têm idade na faixa de $30-39$ anos; quatro $(28,6 \%)$, entre 40-49 anos; um (7,1\%), entre 5059 anos; e um (7,1\%), acima de 60 anos. Três dos sujeitos foram entrevistados por meio do correio eletrônico e os demais o foram pessoalmente.

Essa pesquisa mostrou que as ferramentas de tecnologia de informação e comunicaçáo já fazem parte do cotidiano dos pesquisadores. Todos os entrevistados mencionaram ter computador em casa, o que está de acordo com aquilo que Lévy (1999) e Castells (1999) relatam sobre a evoluçáo das tecnologias da informaçáo e comunicação: rapidamente elas passaram a fazer parte do cotidiano das pessoas, participando hoje de suas atividades pessoais, profissionais e sociais. $\mathrm{O}$ aluno do mestrado relatou ter acompanhado toda a evolução ocorrida nessa área, pois foi um dos usuários de primeira hora dos computadores, antes ainda da revoluçāo provocada pela microinformática na década de 1980 . Na opiniāo desse pesquisador, a utilizaçáo das ferramentas de tecnologia de informação $e$ comunicação é hoje muito mais simples do que quando começou a usá-las.

Apenas um entrevistado declarou não ter acesso doméstico à Internet, opção feita, segundo ele, em função de fatores econômicos (alto custo da assinatura do provedor e do uso da linha telefônica, enquanto na universidade esse acesso é gratuito), pessoais (prefere utilizar seu tempo livre em atividades que não envolvem o uso da rede mundial) e mesmo ideológicos, pois isso acaba gerando sobrecarga de trabalho.

Mudanças na forma de trabalhar, de pensar e de se relacionar, provocadas pela utilização de tecnologias de informaçăo e comunicação também apareceram nos relatos, o que confirma LÉVY (1993). O hábito de rascunhar textos manuscritos está sendo abandonado, em favor da digitaçáo direta em um editor de textos. A hipertextualidade da Internet facilita a busca pela satisfaçăo da curiosidade, mas é também considerada fator de dispersão. E o correio eletrônico, citado por todos como instrumento essencial para o exercício profissional, passou a servir também para manter contatos puramente sociais, substituindo o telefone e o correio tradicional.

Fora do contexto de pesquisa, houve relatos de bate-papo em salas virtuais, leitura de jornais pela Internet, uso de jogos em rede ou locais, obtenção de músicas em formato eletrônico e consulta à programaçáo cultural pela Internet, o que demonstra a participaçáo mais ampla que essas ferramentas têm na vida pessoal e social dessas pessoas, o que está de acordo com o que é encontrado na literatura (BRETAS, 2000; PALACIOS, 1996; LEMOS, 2002). Mas alguns dos entrevistados fizeram questáo de reafirmar
${ }^{3}$ Ferreira, Aurélio Buarque de Holanda. Novo Dicionário Aurélio, Rio de Janeiro: Nova Fronteira, s/d. 
que usam as ferramentas da tecnologia de informação e comunicação apenas no contexto profissional, preferindo investir o tempo livre em leitura, conversa, namoro, boteco ou mesmo tricô. Um deles, apesar de entusiasta dessas ferramentas, colocou o fato de acabar passando muito tempo diante do computador no rol das desvantagens do uso dessa tecnologia.

As ferramentas da tecnologia de informação e comunicaçáo são utilizadas por todos os entrevistados, no exercício de suas atividades de pesquisa, sendo já consideradas imprescindíveis, mesmo por aqueles que não se mostram entusiasmados com elas. A ferramenta mais presente no cotidiano dos entrevistados é, sem dúvida, o correio eletrônico, usado principalmente para troca de informaçóes com colegas de trabalho e pesquisadores de outras instituiçōes, o que só reafirma a importância desse serviço como instrumento de comunicação no trabalho acadêmico. Enquanto isso, outras formas de comunicação eletrônica são praticamente descartadas na atividade de pesquisa. A teleconferência não é utilizada por nenhum deles $\mathrm{e} O$ acesso a salas virtuais (chat) só foi relatado por três entrevistados, sendo que um só o faz como atividade de lazer. O mesmo acontece com as listas e grupos de discussão virtuais, que foram utilizados por apenas três entrevistados, em situação não relacionada à pesquisa em si, e foram logo abandonados por dois deles.

Apesar da a existência de uma preocupação com o uso excessivo de computadores e Internet, isso não foi encontrado no grupo pesquisado, pois a grande maioria dos entrevistados declarou só fazer uso das tecnologias de informação e comunicação em suas atividades de pesquisa e ensino. A grande exceção é o correio eletrônico, usado tanto para contatos profissionais quanto pessoais. Pelo que foi levantado nos relatos, mesmo entre aqueles mais entusiasmados com o uso das novas tecnologias, nenhum dos entrevistados parece se enquadrar no estereótipo de nerd viciado em computador ou Internet. Um dos entrevistados acredita que as salas virtuais são um interessante campo de estudos para os cientistas sociais, por se tratar de um novo espaço social que envolve questōes de grupo e comportamento, mas quase não há pesquisadores da área se dedicando a esse assunto.

\section{Conclusão}

O uso das novas tecnologias de informação e comunicação já se faz presente nas atividades mais corriqueiras do mundo contemporâneo. Entretanto, quando tratamos, no desenvolvimento deste trabalho, dos efeitos que o uso dessas tecnologias provoca na sociedade, é necessário ressaltar o fato de que são ainda efeitos sobre apenas uma pequena parte da sociedade, aquela parte que tem acesso a tais tecnologias. Dados atuais mostram que há ainda um longo caminho a percorrer antes que isso seja realidade para uma parcela significativa da populaçáo mundial, principalmente nos países em desenvolvimento, como éo caso do Brasil. Só então será realmente possível falar em efeitos sobre a sociedade.

É preciso estar atento para o fato de que, mesmo com tais tecnologias assumindo um caráter global, estamos tratando de instrumentos aos quais apenas uma pequena parcela da população mundial tem acesso. $\mathrm{O}$ acesso à Internet, que apresenta uma taxa média de penetraçáo de $25-30 \%$ nos países ricos (sendo de cerca de 50\% nos Estados Unidos, Finlândia e Suécia), é de apenas $3 \%$ na maioria do planeta, com índices menores que $1 \%$ na África e no sul da Ásia (CASTELLS, 2003). De acordo com dados apresentados pela Fundação Getúlio Vargas (NERI, 2003), no Brasil, em 2001, apenas $12,46 \%$ dos brasileiros dispunham de acesso a computador e só $8,31 \%$ estavam conectados à Internet.

Essa é uma realidade em que as tecnologias de informaçăo e comunicação se inserem como mais um fator de divisão da populaçáo entre os que têm e os que não têm, mais um elemento de exclusão da maior parte da sociedade, o que implica em fragilidade no mercado de trabalho e perda de competitividade econômica. Implica também em baixa capacidade educativa e cultural de uso da Internet, 
ou seja, de "saber onde está a informação, como buscá-la, como transformá-la em conbecimento especifico para fazer aquilo que se quer fazer" (CASTELLS, 2003, p. 267), uma vez que essa capacidade de aprender a aprender é socialmente desigual e ligada à origem social e familiar, bem como ao nível cultural e de educação (CASTELLS, 2003). A democratização do uso das novas tecnologias da informação e comunicação é essencial para a inserção de parcelas marginalizadas da população.

O que parece ficar claro é que o fenômeno da disseminação das tecnologias de informação e comunicação traz implicaçōes sociais que aguçam a curiosidade dos pesquisadores, mas também que ainda é necessária a realização de maiores estudos sobre os efeitos físicos, cognitivos, comportamentais e sociais dessas novas tecnologias na nossa sociedade, uma vez que é muito recente sua inserção na vida das pessoas. $\mathrm{O}$ ciberespaço possibilita novas formas de relação e socialização, cuja compreensão está apenas começando, necessitando inclusive do desenvolvimento de instrumentos de investigação apropriados.

\section{Abstract}

Technologies, in spite of being a product from our society, they also contribute to its transformation and conformation. This article presents some of the effects of information and communication technologies (ICTs) dissemination on the society: personal, professional and social life. Our conclusion is that these effects need to be further analysed because the introduction of ICTs is still on its early stages.

Key words: information and comunication technologies, effects, society.

\section{Referência}

BAWA, Joanna. Computador e saúde - manual do usuário: problemas, prevenção e cura. São Paulo: Summus, 1997.230p.

"BERGER, Peter L;; LUCKMANN, Thomas. A construção social da realidade. Petrópolis: Vozes, 2002. 247p. BRETAS, Maria Beatriz Almeida Sathler. Interações telemáticas: um estudo sobre jovens internautas de Belo Horizonte. Tese (Doutorado em Ciência da Informação) - Escola de Ciência da Informação, Universidade Federal de Minas Gerais, Belo Horizonte, 2000. 231p.

'CASTELLS, Manuel. A revolução da tecnologia da informação. In: CASTELLS, Manuel. A sociedade em rede. São Paulo: Paz e Terra, 1999, p. 49-86. . Internet e sociedade em rede. In:

MORAES, Denis de (org.). Por uma outra comunicação: mídia, mundialização cultural e poder. Rio de Janeiro: Record, 2003, p. 255-287.

LEMOS, André. Aspectos da cibercultura: vida social nas redes telemáticas. In: PRADO, José Luiz Aidar (org.). Crítica das práticas midiáticas. São Paulo: Hacker Editores, 2002, p. 111-129.

LÉVY, Pierre. As tecnologias da inteligência: o futuro do pensamento na era da informática. São Paulo: Editora 34, 1993. 203p.

\section{260p.}

Cibercultura. São Paulo: Editora 34,

MARQUES NETO, Humberto Torres. A tecnologia da informação na escola. In: COSCARELLI, Carla Viana (org.). Novas tecnologias: novos textos, novas formas de pensar. Belo Horizonte: Autêntica, 2002. p.51-63.

MARTÍN-BARBER0, Jesús. Globalização comunicacional e transformação cultural. In: MORAES, Denis de (org.). Por uma outra comunicação: mídia, mundialização cultural e poder. Rio de Janeiro: Record, 2003, p. 57-86.

MENOU, Michel J. Impacto da Internet: algumas questões conceituais e metodológicas, ou como acertar um alvo em movimento atrás da cortina de fumaça. Datagrama Zero, n.0, dez/99. Disponivel em: http://www.dgzero.org/dez99/ F_I_art.htm. Acessado em: 10/7/2003.

NERI, Marcelo Côrtes (coord.). Mapa da exclusão digital. Rio de Janeiro: FGV/IBRE, 2003. Disponível em: http://www2.fgv.br/ibre/cps/mapa_exclusao/ apresentacao/apresentacao.htm. Acessado em: 05/ 01/2004.

OLIVEIRA, José Palazzo Moreira de. Sistemas de informação e sociedade. Ciência e Cultura, São Paulo, v. 55, n. 2, p. 39-41, 2003. Disponivel em: http:// www.inf.ufrgs.br/ palazzo/docs/Artigos/03 SBPC.pdf. Acessado em: 25/10/2003.

PALACIOS, Marcos. Cotidiano e sociabilidade no ciberespaço: apontamentos para discussão. In: FAUSTO NETO, Antônio; PINTO, Milton José. O individuo e as midias. Rio de Janeiro: Diadorim, 1996, p. 87102.

PALMQUIST, Ruth A. The impact of information technology on the individual. Annual Review of Information Science and Technology, v. 27, p. 2-42, 1992.

RIBEIRO, José Carlos. Um breve olhar sobre a sociabilidade no ciberespaço. In: S. LEMOS, André; PALACIOS, Marcos (orgs.). As janelas do ciberespaço. Porto Alegre: Sulina, 2001, p. 138-150.

SFEZ, L. Informação, saber e comunicação. Informare: Cadernos do Programa de Pós-Graduação em Ciência da Informação, Rio de Janeiro, v.2, n.1, p. 5-13, 1996.

WEIL, Pierre. A normose informacional. Ciência da Informação, Brasília, v. 29, n.2, 2000. Disponivel em: http://www.ibict.br/cionline/290200/ 29020008.htm. Acessado em: 4/6/2003. 